\title{
Willingness to Pay among Swedish Households to Avoid Power Outages \\ - A Random Parameter Tobit Model Approach
}

\author{
Fredrik Carlsson ${ }^{A}$ \\ Peter Martinsson ${ }^{\mathrm{B}}$ \\ Working Papers in Economics no. 154 \\ December 2004 \\ Department of Economics \\ Gothenburg University
}

\begin{abstract}
Using a contingent valuation survey, we elicit Swedish households' willingness to pay (WTP) to avoid power outages. In the study respondents are asked to state their WTP for avoiding nine different types of outages. We therefore apply a random parameter Tobit model since there is cross-sectional heterogeneity and a proportion of zero responses. Based on the estimations, we find that the WTP depends positively on the duration of the outages, and that WTP is significantly higher for unplanned outages. The overall variation in the WTP due to observed heterogeneity in housing and socio-economic variables is small compared to the pure effects of power outages. Policy implications of those findings are discussed.
\end{abstract}

JEL Classification: C25, C93, D12, Q41

Key-words: Power outages; Contingent Valuation; Random parameters; Tobit model.

\footnotetext{
Acknowledgment: Financial support from Elforsk is gratefully acknowledged. The paper has benefited from comments from Håkan Eggert, Peter Fritz, Peter Frykblom, Lennart Hjalmarsson, Anders Johansson, Olle Hansson, Per-Olof Nilsson, Håkan Nyberg, Thomas Sterner and Matz Tapper.

A Department of Economics, Göteborg University, Box 640, 40530 Göteborg, Sweden; Ph +46 31 7734174; Fax +46 3177310 43; E-mail fredrik.carlsson@economics.gu.se.

B Department of Economics, Göteborg University, Box 640, 40530 Göteborg, Sweden; Ph +46 31 7735255; Fax +46 3177310 43; E-mail peter.martinsson @economics.gu.se.
} 


\section{Introduction}

At a first glance, power outages for households in a developed country such as Sweden might seem to be a small problem since the outages that households experience are both few in numbers and short in duration. ${ }^{1}$ However, households have over the years become more and more dependent on electricity because of an increased use of electronic items and because people work from their homes to a larger extent than before.

In 1996, the reformation of the Swedish electricity market began when the electricity sector changed from being a completely regulated domestic market to a now completely liberalized Nordic-wide market with the major exception being the transmission of electricity. One part of the electricity bill paid by households relates to the tariff for the transmission of electricity, and the level of the tariff is determined by the network companies, since there is no market for the transmission of electricity. However, the tariffs charged by the network companies have to be "reasonable" according to Swedish Law, and in order to judge whether or not the tariff charged is reasonable, the so-called network performance assessment model has been developed. In this model, the actual tariffs charged are divided by the calculated value of the services from the network performance assessment model. If the obtained ratio exceeds unity, then the network company has charged more than the value of the services provided to its customers and vice versa. In cases when the network companies have over-charged their customers, they have had to pay back the same amount to their customers. In the aftermath of the electricity market liberalization, there are also concerns that power outages will increase. The experiences from the deregulation of the electricity market in many of the states in the USA during the last 10 years have shown that it is not evident that the number of outages will remain at a low level. Instead it seems that the deregulation per se in connection with congested transmission grids, have resulted in an increased number of outages and blackouts in the USA (Faruqui et al., 2001; Joskow, 2001). Moreover, more extreme weather conditions such as hurricanes are also to be blamed for the increased number of outages. Since the reform of the

\footnotetext{
${ }^{1}$ Swedish households located in populated areas experienced an average of 0.08 planned power outages per year and 0.39 unplanned power outages per year during the 1998-2001 period with an average duration of 12 and 23 minutes, respectively (Svenska Kraftnät, 2002). The corresponding figures for households in sparsely populated areas of Sweden are 0.60 planned and 1.54 unplanned power outages per year with average durations of 83 and 203 minutes, respectively.
} 
electricity market in Sweden, there has been a closure of reserve capacity as a response to reduce costs (Svenska Kraftnät, 2002).

Given the liberalization, more extreme weather conditions and an increased dependence on electricity, it is of importance for the regulators to obtain information about households welfare losses from power outages, not the least to facilitate a proper design of the performance-based regulation model. In this paper we report the results of a contingent valuation study that aims at estimating the willingness to pay (WTP) among Swedish households for the reduction of power outages with various characteristics, such as the duration and whether the outage is known beforehand or not. In the study respondents are asked to state their WTP for avoiding nine different types of outages. There are therefore two important econometric issues that need to be addressed in the analysis. We obtain several responses from each individual, which means that there is a cross-sectional heterogeneity, and thus a standard OLS would result in inefficient parameter estimates. In addition, there is a possibility of stating zero WTP in the survey, so we also need to consider the censoring aspect when analyzing the responses. In the econometric analyses we apply a random parameter panel Tobit model to consider both the issue of zero WTP and cross-sectional heterogeneity. Estimation of this type of model is complex since it involves calculation of high-dimensional probability integrals (Moeltner and Layton, 2002). However, a development of simulation methods has occurred over the few last years, making it easier to estimate this type of model.

In the next section we discuss different approaches that have been used to measure the cost of power outages followed by a description of the design of our survey and of the econometric approach used in the estimations. Section 3 contains a presentation of the results and a comparison of our results with previous findings. The final section concludes the paper.

\section{The Contingent Valuation Study}

There are in principle three different approaches that can be used to measure the cost of power outages to households. The first approach involves directly asking households to specify their costs for various types of outages (see for example Wacker et al., 1985; Doane et al., 1988a; SINTEF, 2003). The second is to study the actual behavior of 
households in terms of investments aiming at mitigating power outages. The third is to either directly or indirectly asking the households about their WTP to avoid power outages by using a stated preference approach (see e.g. Beenstock et al., 1998; Doane et al., 1988b; Layton and Moeltner, 2004; Svenska Elverksföreningen, 1994). There are clearly pros and cons of either asking for the costs of outages or of avoiding outages, or of asking for the WTP of avoiding outages. The main difference between the approaches is that it is only the latter that considers all welfare effects by including nonmarket effects. For example, individuals may not be able to watch their favorite programs on TV or to cook during an outage. While these negative effects do not have direct monetary effects, they do clearly impact people's welfare. An example of direct monetary effects would be that food will be spoiled if the freezer stops working.

It is of course cognitively more demanding for the respondents to state the welfare effects in terms of WTP rather than reporting the actual monetary cost caused by a power outage. Since we expect that a large impact on households welfare from outages relates to non-market effects, we apply a contingent valuation survey. In a contingent valuation survey, which is the most commonly applied of the stated preference methods, each respondent is asked about his/her WTP for a certain scenario. There are several ways in which the question about the respondent's WTP can be posed, but let's here only distinguish between open-ended and closed-ended formats. With an open-ended format, respondents are asked to state their maximum WTP, while with a closed-ended format, respondents answer whether or not their WTP is equal to or higher than a certain proposed bid. There are pros and cons with both of these formats and in this paper we have chosen to use the open-ended format. Using a closed-ended design would be more difficult, although not impossible, since we would have to introduce a bid for each outage reduction presented to the respondent. Other reasons for choosing an open-ended format are that the informational content of each response is higher compared with a closed-ended format, and that we avoid respondents anchoring their answers on a certain bid level. At the same time, there are criticisms against the open-ended format, in particular relating to the problems of incentive compatibility (Carson et al., 2000) and that it does not resemble an actual purchase decision, i.e. we do not state our maximum WTP for a good when we go shopping. The general tendency that has been found in the literature is that the open-ended format results in lower WTP estimates than the closed- 
ended format; see for example Brown et al. (1996) and Kriström (1993). Furthermore, there are experimental results showing that the hypothetical bias - the bias introduced by asking a hypothetical question and not confronting the respondent with a real situation - is not higher, or even lower, for the open-ended format compared with the closed-ended format (List and Gallet, 2001; Baliestreri et al., 2001).

In the survey, the respondents were asked to state their maximum WTP for avoiding one power outage of a certain duration starting at $6 \mathrm{pm}$ on an evening in January. This scenario was chosen because the previous study conducted in Sweden on power outages in 1992 used this scenario (Svenska Elverksföreningen, 1994), but also because this scenario represents a worst case. In the contingent valuation survey, we included both planned and unplanned outages with durations of 1, 4 and 8 hours, which also correspond to the durations examined in the previous Swedish outage cost study. In addition, we were also interested in examining the WTP for very long power outages and therefore a 24 hour outage was included. For unplanned outages we also included a valuation question asking for the maximum WTP when there is uncertainty about the duration of the outage in the 2 to 6 hours range. It was clearly stated that the probability that the duration of the power outage would last 2 hours, 6 hours, or any duration inbetween, was the same. In fact, this is how most unplanned outages are perceived and therefore it is of interest to see if the case of uncertainty, with an average duration of 4 hours, results in a higher WTP compared with a definite 4 hour outage.

The scenario and the contingent valuation questions are presented below in Figure 1. The respondents were explicitly told that for each valuation question they should answer how much their household would be willing to pay in order to avoid one power outage with the characteristics mentioned in the question.

\section{>> FIGURE 1}

There are a number of econometric challenges to be addressed when analyzing the responses. First of all, for each valuation question there are a number of "zero" responses, i.e. respondents stating a zero WTP. These responses should, without any further information, be treated as true zeros since we can not rule out a WTP equal to zero. Second, the data have a panel-structure since we observe the WTP for a household 
for a number of different cases of power outages. Although the characteristics of the power outages vary, it is likely that there will be cross-sectional heterogeneity. For example, an individual who has a relatively high WTP for a short outage compared with others is also likely to have a relatively high WTP for a longer outage, and similarly an individual who has a zero WTP for a certain outage is more likely to have a zero WTP for another outage. In order to consider both zero WTP and cross-sectional heterogeneity, we apply the following general censored model:

$$
\begin{gathered}
W T P_{i j}^{*}=\alpha_{i}+\beta_{i} t_{j}+\gamma x_{i}+\varepsilon_{i j} ; \varepsilon_{i j} \sim N\left[0, \sigma^{2}\right] \\
W T P_{i j}=\max \left\{0, W T P_{i j}^{*}\right\},
\end{gathered}
$$

where $W_{T P}^{*}$ is the latent value of individual $i$ 's WTP in treatment $j$ with an outage duration of $t_{j}, x_{i}$ is a vector of socio-economic characteristics, and $W T P_{i j}$ is the observed value of individual i's WTP. By including the socio-economic characteristics in the WTP function, we allow for observed heterogeneity in WTP. In addition, we also allow for unobserved heterogeneity by estimating a random parameter model. ${ }^{2}$ Illustrating this with the duration parameter, we have that the parameter is the sum of the population mean, $\bar{\beta}$, and the respondent deviation, $\widetilde{\beta}_{i}$, such that $\beta_{i}=\bar{\beta}+\widetilde{\beta}_{i}$. These respondent deviations are assumed to be normally distributed with mean zero and a standard deviation. Consequently, for the parameters that are randomly distributed, we estimate both a mean and a standard deviation parameter. The standard deviation parameter is then assumed to capture unobserved preference heterogeneity. We assume that the randomly distributed parameters are constant across the valuation questions for each respondent. This reflects an underlying assumption of stable preference structure for each respondent when answering the set of valuation questions. In addition, we assume that the intercept is randomly distributed, which is the equivalent of a random effects panel data model. Estimation of this type of model is difficult in the sense that the likelihood function involves evaluation of high-dimensional multivariate integrals,

\footnotetext{
${ }^{2}$ For an excellent overview of random paramater models, see Train (2003), and for a recent application of a random parameter model with censored data, see Moeltner and Layton (2002).
} 
which in turn means that we have to rely on simulation methods for the probabilities (Train, 2003).

The final questionnaire consisted of three parts. The first part contained questions about the households' housing considerations, to what extent they rely on electricity and their general views on power outages. The second part consisted of the contingent valuation survey and the last part contained socio-economic questions. The questionnaire was developed in collaboration with representatives from various power companies and experiences power outage researchers. Before the questionnaire was finalized, it was tested in smaller focus groups followed by a large pilot study mailed to 1,000 individuals.

\section{Results}

Our sample was randomly drawn from a register containing all individuals between the ages of 18 and 75 years with a permanent address in Sweden. The survey was sent out to 3,000 randomly selected individuals in 2004. Of these, 19 were returned because of address unknown. ${ }^{3}$ In total, 1,678 (56\%) individuals returned the questionnaire. However, not all of them answered all nine contingent valuation questions and we excluded all individuals who answered less than three of the valuation questions. Since there is a rather large share of zero responses and most respondents stated a rather low WTP, the mean WTP is very sensitive to a few extreme responses. In addition, there are a number of non-responses to various other questions, resulting in 1,488 responses available for the analyses. ${ }^{4}$

Before the valuation questions, the respondents were asked to rate how unpleasant a number of effects from a power outage in January would be for them. According to the respondents, the most unpleasant effects would be falling indoor temperatures and refrigerators and freezers not working. This was followed by not being able to cook and not having any light. The least important effects were: not to be able to use the

\footnotetext{
310 days after the questionnaire was sent out, a reminder was sent out including a copy of the questionnaire.

${ }^{4}$ Comparing the sample statistics with Swedish population statistics shows no statistical difference at the $5 \%$ level related to gender composition ( $p$-value $=0.28$ ) and to the geographical representation of the respondents ( $\mathrm{p}$-value $=0.90$ ), where the latter was based on dividing the country into ten parts based on the postal code. However, there is a significant overrepresentation of older people (95\% confidence interval of age is 47.11-48.55 in our sample while the average age in the Swedish population aged 18-75 years is 44.88) (SCB, 2004).
} 
computer and that the risk of accidents would increase. Thus, this shows that several of the negative effects caused by power outages are related to non-monetary effects.

Below in Table 1, we present the descriptive statistics of the WTP responses to the various valuation questions, where the values are presented in SEK/Outage. ${ }^{5}$

\section{>> TABLE 1}

The results are expected and consistent in the sense that the mean WTP increases and the share of zero WTP decreases when the duration of the power outage increases. In case of a planned outage, the WTP to avoid one outage increases from 6.30 SEK for a one hour duration to 189.25 SEK for a 24 hour outage, while the corresponding figures for unplanned outages are 9.39 SEK and 223.01 SEK, respectively. Furthermore, the WTP is higher for unplanned outages compared with planned outages. Our design also makes it possible to study the impact on WTP of uncertainty about the duration of the power outage in the range 2 to 6 hours with equal probability of ending at any time during this period. The expected duration in the uncertainty case is 4 hours and the WTP is 68.80 SEK. This figure should be compared with the WTP of 37.32 SEK for an unplanned outage that ends for sure after exactly 4 hours. Thus, the WTP is almost twice as high in the case of uncertainty. This suggests that respondents put a high value on avoiding uncertainty. One interesting finding from the stated WTP is that a large share of the respondents stated a zero WTP. This in turn means that the distribution of the WTP in the sample is skewed and that the median is much lower than the mean, and that for many of the outage durations the median WTP is zero. ${ }^{6}$ One can perhaps argue that the share of respondents with zero WTP is too high. Two possible explanations for the high share are that these respondents are protesting either against the scenario itself or against the principle that they should pay for something that they feel they are entitled to. The latter was something that was expressed both in focus groups and in written comments in the questionnaire. However, it should be stressed that elicitation of preferences is always done in a context; in our case the context is that the customer should pay for a reduction in the number of outages. Since this is the typical scenario

\footnotetext{
${ }^{5}$ The exchange rate at the time of the survey was 1 USD $=7.5$ SEK.

${ }^{6}$ From a welfare theoretic point of view, using the mean is equivalent to applying the Hicks-Kaldor compensation principle. Adoption of the median, when aggregating the values, is equivalent to applying a majority voting rule.
} 
presented in the valuation studies on power outages our results are still comparable to other studies.

It is also of interest to compare our results with the results from the most recent Swedish outage study (Svenska Elverksföreningen, 1994). This study was conducted in 1992 and it also applied an open-ended CV study with a scenario very similar to ours. There is one important difference: in our case the outage is stated to start at $6 \mathrm{pm}$, while in the previous study during the afternoon. In order to make comparison simpler, the results from both studies are expressed in 2003 prices.

>> TABLE 2

The WTP for avoiding a power outage has increased over the last 10 years. Our results seem to be in line with what others have found. For example, in a recent Norwegian study the average increase in real outage cost was found to be 80\% between 1991 and 2002 (SINTEF, 2003). ${ }^{7}$

Let us turn to the econometric analysis of the determinants of the WTP for avoiding power outages. The descriptive statistics of the sample are presented in Table 3 below.

\section{>> TABLE 3}

Since there are reasons to believe that the WTP for a certain duration is different for planned and unplanned outages, we estimate a WTP function that allows for differences in valuation between these two cases of outages. Furthermore, both the WTP and the independent continuous variables are in log-form. ${ }^{8}$ In addition, we treat the WTP for 24 hour outages separately by including a dummy variable for this outage and setting the

\footnotetext{
${ }^{7}$ At the same time, the mean WTP estimtates in the Norwegian study are much higher than the mean WTP estimates in our study. We can also compare our mean estimates with various US studies. Layton and Moeltner (2004) report and compare results from various US studies and our estimates of mean WTP for an outage is much lower than these estimates obtained in these US studies. For example, Layton and Moeltner find a mean WTP of almost 300 SEK for an unplanned 8 hour outage. This is almost 3 times as high as our estimated mean WTP.

${ }^{8}$ As discussed by Moeltner and Layton (2002), it is common in the litterature to assume that both WTP and duration are in log-form. The main reason is that it implies a concave and monotonically increasing relationship between WTP and duration. Since there is a number of observations with zero WTP, we actually recode the WTP values before the log-tranformation by adding the value 1 to all observations. The dependent variable will then become $\ln (W T P+1)$. This also means that the censoring at 0 still is valid since $\ln (1)=0$.
} 
duration variable to zero. This is done because we expect that a long outage is perceived differently than shorter outages. The intercept and the four outage duration coefficients are assumed to be normally distributed. All models are estimated using simulated maximum likelihood with 250 Halton draws, and the results are presented in Table 4 below. ${ }^{9}$

\section{>> TABLE 4}

The duration parameters, both for unplanned and planned outages are significant and the uncertainty duration parameter is significant as well. These findings are in line with the descriptive statistics presented in Table 1 . The standard deviations are significant except for the duration of planned outages, although they are relatively small compared with the mean parameters. Thus, we are able to capture unobserved heterogeneity in terms of a general difference in the WTP for power outages among the respondents but also for differences in terms of the WTP for various cases of power outages. ${ }^{10}$

If we look at observed heterogeneity, there are some interesting findings. The uncertainty about the duration of the outages results in a higher WTP, which clearly shows that information about the expected length of a power outage is very important for the households. In reality, the durations of planned outages are in most cases known, but for unplanned ones they are not. Thus, this would then mean that the "true" WTP to reduce an unplanned power outage of the durations presented is higher since the duration in reality is uncertain (or unknown). Respondents who do not live in a larger city have significantly lower WTP. One interpretation of this result is that those who live outside larger cities are likely to suffer more frequently from outages and thus are more used to outages and hence better prepared for them. Respondents who live in detached or terraced houses are willing to pay more than others, and if there is no possibility of heating the house during a power outage, the WTP is also significantly higher. Older respondents have lower WTPs and female respondents also have lower WTPs. The income elasticity for WTP is around 0.2 (not shown in table) which means

\footnotetext{
${ }^{9}$ See Train (2003) for an introduction to simulated maximum likelihood estimation. All models in the paper are estimated with Limdep 8.

${ }_{10}$ The random parameter Tobit model nests the fixed coefficents Tobit model, which means we can use a likelihood ratio test of the null hypothesis that the standard deviations are zero. In both cases we can reject the null hypothesis at a $1 \%$ significance level.
} 
that a $10 \%$ increase in income increases the WTP by $2 \% .{ }^{11}$ Note, however, that this is the income elasticity for WTP and not for demand. It can be shown that under certain restrictions, the income elasticity of WTP is always lower than the demand elasticity (Carson et al., 2001). Furthermore, the income elasticity of WTP is comparable with those obtained in other Swedish WTP studies on e.g. improvements of air quality (Carlsson and Johansson-Stenman, 1999) and reduction of transport risks (Carlsson et al., 2004). Overall, what mainly seems to drive the WTP of an outage is its duration, while the other significant variables have a relatively small marginal effect on the WTP.

Based on the estimated WTP function, we calculate the predicted WTP for outages of different durations using the estimated relationship between the WTP and outage duration, and this is done using sample means for all the other variables in the WTP functions. We calculate the predicted WTP for durations between 1 and 8 hours. In order to calculate predicted WTP, we first need to convert the expected latent log WTP into expected censored log WTP, or in other words, we need to calculate the first moment of the censored normal variable log WTP (Greene, 2002). Then we convert the log WTP into absolute WTP. Note that we cannot simply take the exponent of the expected log WTP since that would result in a log-transformation bias (Goldberger, 1968). Several transformation procedures have been suggested in the literature (see e.g. Stynes et al., 1986). In our case we follow Moeltner and Layton (2002) and Woo and Train (1988) by multiplying the expected log WTP with a transformation term that is based on the actual observations of the WTP. The transformation term that we use is the ratio between the actual WTP and the exponent of the expected log WTP. For durations that we do not observe, we make a simple linear interpolation between the observed points of the transformation term. This means that for the durations 1, 4 and 8 hours the expected WTP is equal to the observed WTP. The results of these calculations are presented in Table 5, where we also have included the $95 \%$ confidence interval. ${ }^{12}$ For all durations, mean WTP is significantly different between planned and unplanned outages at a $10 \%$ level.

\footnotetext{
${ }^{11}$ Since both WTP and income are in log form, the income elasticity is equal to the marginal effect of the income variable.

12 The confidence intervals were obtained by using the bootstrap technique. 1488 individuals were randomly drawn with replacement, then the Tobit model was re-estimated and WTP values were calculated. This was repeated 500 times. Since each Tobit model takes a relatively long time to estimate, the models were estimated with 20 Halton draws instead of 250 draws.
} 
>> TABLE 5

\section{Conclusions}

The liberalization of the electricity market, the development of new regulation tools, and increased dependence on electricity are all factors that point to the importance of studying the welfare effects of power outages. The contingent valuation study that we have undertaken reveals some interesting information about the WTP among Swedish households to avoid power outages. First of all, the inflation adjusted WTP to avoid a power outage has increased compared to the previous Swedish study. From an international perspective the WTP to avoid power outages seems to be substantially lower than the corresponding estimates in similar countries such as Norway and the US. There is a significant difference in WTP for planned and unplanned outages. The uncertainty about the duration of the outages is also an important determinant of the WTP, and this clearly points to the fact that information about the expected length of an outage is very important for households. This in turn means that the true values for unplanned outages are probably higher. Using a random parameter Tobit model, we estimate WTP functions for planned and unplanned outages. We find that the WTP varies significantly in the population. Respondents defined by for example age, geographic location, income, gender and type of housing have different WTPs for outages. In summary, our results point to a large heterogeneity in WTP for outages, where for example $90 \%$ of the households were not willing to pay anything to avoid a one hour planned power outage. Moreover, our results show that it is important that the network performance assessment model considers the differences between planned and unplanned outages. 


\section{References}

Balisteri, E, G. McClelland, G. Poe and W. Schulze (2001). Can Hypothetical Questions Reveal True Answers? A Laboratory Comparison of Dichotomous Choice and Open-ended Contingent Values with Auction Values, Environmental and Resource Economics 18, 275-292.

Beenstock, M., E. Goldin and Y. Haitovsky (1998). Response Bias in a Conjoint Analysis of Power Outages, Energy Economics 20, 135-156.

Brown, T., P. Champ, R. Bishop and D. McCollum (1996). Which Response Format Reveals the Truth about Donations to a Public Good?, Land Economics 72, 152166.

Carlsson, F. and O. Johansson-Stenman (2000). Willingness to Pay for Improved Air Quality in Sweden, Applied Economics 32, 661-670.

Carlsson, F., O. Johansson-Stenman and P. Martinsson (2004). Is Transport Safety more Valuable in the Air?, Journal of Risk and Uncertainty 28, 147-163.

Carson, R., T. Groves and M. Machina (2000). Incentive and Information Properties of Preference Questions, Working Paper, Department of Economics, University of California.

Carson, R., N. Flores and N. Meade (2001). Contingent Valuation: Controversies and Evidence, Environmental and Resource Economics 19, 173-210.

Doane, M., R. Hartman and C-K. Woo (1988a). Household Preference for Interruptible Rate Options and the Revealed Value of Service Reliability, Energy Journal 9, 122-133.

Doane, M., R. Hartman and C-K. Woo (1988b). Households' Perceived Value of Service Reliability: An Analysis of Contingent Valuation Data, Energy Journal 9, 135-151.

Faruqui, A., H-P. Chao, V. Niemeyer, J. Platt and K. Stahlkopf (2001). Analyzing California’s Power Crisis, Energy Journal 22, 29-52.

Goldberger, A. (1968). The Interpretation and Estimation of Cobb-Douglas Functions, Econometrica 35, 464-472.

Greene, W. (2000). Econometric Analysis. Prentice-Hall, New Jersey.

Joskow, P. (2001). California's Energy Crisis, Oxford Review of Economic Policy 17, 365-388.

Kriström, B. (1993). Comparing Continuous and Discrete Contingent Valuation Questions, Environmental and Resource Economics 3, 63-71.

Layton, D. and K. Moeltner (2004). The Cost of Power Outages to Heterogeneous Households - An Application of the Gamma-Lognormal Distribution, in A. Alberini and R. Scarpa (Eds.) Applications of Simulation Methods in Environmental and Resource Economics, Kluwer Academic Press.

List, J. and C. Gallet (2001). What Experimental Protocol Influence Disparities between Actual and Hypothetical Stated Values?, Environmental and Resource Economics 20, 241-254.

Moeltner, K. and D. Layton (2002). A Censored Random Coefficients Model for Pooled Survey Data with Application to the Estimation of Power Outage Costs, Review of Economics and Statistics 84, 552-561.

SINTEF (2003). Sluttbrukeres kostnader forbundet med strömdbrudd og spenningsforstyrrelser, SINTEF Energiforskning AS TR A5752 (in Norwegian).

Stynes, D., G. Peterson and D. Rosenthal (1986). Log Transformation Bias in Estimating Travel cost Models, Land Economics 72, 94-103. 
Svenska Elverksföreningen (1994). Avbrottskostnader för Elkunder. Svenska Elverksföreningen, Stockholm (in Swedish).

Svenska Kraftnät (2002). Ett Robust Elförsörjningssystem. Svenska Kraftnät, Stockholm (in Swedish).

Train, K. (2003). Discrete Choice Methods with Simulation. Cambridge University Press, New York.

Wacker, G, R. Subramaniam and R. Billington (1985). Using Cost of Electric Service Interruption Surveys in the Determination of a Composite Customer Damage Function, International Journal of Energy Systems 5, 100-104.

Woo, C-K. and K. Train (1988). The Cost of Electric Power Interruptions to Commercial Firms, Energy Journal 9, 161-172. 
Table 1. Willingness to pay results, SEK/Outage.

\begin{tabular}{|c|c|c|c|c|c|c|}
\hline & & Mean & Stdv & Median & Max & $\begin{array}{c}\text { Share of } \\
\text { zero WTP }\end{array}$ \\
\hline \multirow{4}{*}{$\begin{array}{l}\stackrel{D}{\mathscr{E}} \\
\stackrel{\Xi}{\Xi}\end{array}$} & 1 hour & 6.30 & 39.23 & 0 & 500 & 0.90 \\
\hline & 4 hours & 28.46 & 99.86 & 0 & 1000 & 0.74 \\
\hline & 8 hours & 84.42 & 202.01 & 0 & 2000 & 0.51 \\
\hline & 24 hours & 189.25 & 377.09 & 50 & 3000 & 0.39 \\
\hline \multirow{5}{*}{ 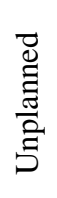 } & 1 hour & 9.39 & 45.14 & 0 & 500 & 0.86 \\
\hline & 4 hours & 37.32 & 101.91 & 0 & 750 & 0.68 \\
\hline & 8 hours & 108.09 & 239.52 & 15 & 2000 & 0.46 \\
\hline & 24 hours & 223.01 & 430.59 & 90 & 3000 & 0.36 \\
\hline & Between 2 and 6 hours & 68.80 & 168.22 & 0 & 1200 & 0.59 \\
\hline
\end{tabular}


Table 2. Comparison with 1994 outage cost study, 2003 prices. SEK/Outage.

\begin{tabular}{lcccc}
\hline & Duration & $\mathbf{1 9 9 4}$ & $\mathbf{2 0 0 3}$ & Increase (in \%) \\
\hline Planned & 1 hour & 2.60 & 6.3 & 142 \\
& 4 hours & 8.76 & 28.46 & 225 \\
\multirow{3}{*}{ Unplanned } & 8 hours & 36.22 & 84.42 & 133 \\
& 1 hour & 5.68 & 9.39 & 65 \\
& 4 hours & 21.54 & 37.32 & 73 \\
& 8 hours & 60.60 & 108.09 & 78 \\
\hline
\end{tabular}


Table 3. Descriptive statistics

\begin{tabular}{|c|c|c|c|}
\hline Variable & Description & Mean & Standard deviation \\
\hline & Geographic location & & \\
\hline Larger city & $=1$ if more than 100,000 inhabitants & 0.30 & 0.46 \\
\hline City & $=1$ if $1,000-100,000$ inhabitants & 0.55 & 0.50 \\
\hline Countryside & $\begin{array}{l}=1 \text { if less than } 1,000 \text { inhabitants } \\
\text { Housing }\end{array}$ & 0.15 & 0.35 \\
\hline House & $=1$ if detached or terraced house & 0.63 & 0.48 \\
\hline Apartment & $\begin{array}{l}=1 \text { if apartment block } \\
\text { Heating }\end{array}$ & 0.37 & 0.48 \\
\hline Can heat & $=1$ if house can be heated during outage & 0.59 & 0.49 \\
\hline Cannot heat & $\begin{array}{l}\quad=1 \text { if house cannot be heated during outage } \\
\text { Socio-economic characteristics }\end{array}$ & 0.40 & 0.49 \\
\hline Age & Age in years & 49.38 & 15.09 \\
\hline Female & $=1$ if female respondent & 0.47 & 0.50 \\
\hline Income & Monthly household income after tax & 25101 & 11528 \\
\hline
\end{tabular}


Table 4. Results of random parameter Tobit model.

\begin{tabular}{lcccc}
\hline & \multicolumn{2}{c}{ Parameter } & \multicolumn{2}{c}{ Standard deviation } \\
\hline \multicolumn{1}{c}{ Random parameters } & Coeff & P-value & Coeff & $P$-value \\
Intercept & -6.629 & 0.000 & 4.509 & 0.000 \\
Log Duration (hours): planned & 2.296 & 0.000 & 0.023 & 0.262 \\
Log Duration (hours): unplanned & 2.610 & 0.000 & 0.329 & 0.000 \\
24 hour outage: planned & 6.685 & 0.000 & 0.433 & 0.000 \\
24 hour outage: unplanned & 6.982 & 0.000 & 0.165 & 0.000 \\
$\quad$ Fixed parameters & & & & \\
Uncertainty & 0.775 & 0.000 & & \\
Medium city & -0.084 & 0.042 & & \\
Countryside & -1.332 & 0.000 & & \\
House & 0.137 & 0.002 & & \\
Cannot heat & 0.508 & 0.000 & & \\
Log Age & -1.643 & 0.000 & & \\
Female & -0.787 & 0.000 & & \\
Log Income & 0.804 & 0.000 & & \\
Variance parameter & 2.150 & 0.000 & & \\
\hline Restricted log-L & -29867 & & \\
log-L & -15518 & & \\
Number of obs & 13040 & & \\
Number of individuals & \multicolumn{5}{c}{1488} \\
\hline
\end{tabular}


Table 5. Predicted WTP in SEK/outage at various outage durations, 95\% confidence intervals in parentheses.

\begin{tabular}{|c|c|c|}
\hline Duration (hours) & Planned outage & Unplanned outage \\
\hline 1 & $\begin{array}{c}6.30 \\
(4.30-10.32)\end{array}$ & $\begin{array}{c}9.39 \\
(7.52-15.95)\end{array}$ \\
\hline 2 & $\begin{array}{c}12.37 \\
(9.55-16.72)\end{array}$ & $\begin{array}{c}16.27 \\
(13.60-22.55)\end{array}$ \\
\hline 3 & $\begin{array}{c}18.18 \\
(15.74-25.95)\end{array}$ & $\begin{array}{c}25.19 \\
(21.97-32.56)\end{array}$ \\
\hline 4 & $\begin{array}{c}28.46 \\
(23.46-38.20)\end{array}$ & $\begin{array}{c}37.32 \\
(33.87-48.21)\end{array}$ \\
\hline 5 & $\begin{array}{c}38.45 \\
(32.41-49.44)\end{array}$ & $\begin{array}{c}48.76 \\
(45.27-63.43)\end{array}$ \\
\hline 6 & $\begin{array}{c}50.83 \\
(44.08-63.71)\end{array}$ & $\begin{array}{c}63.86 \\
(60.48-84.49)\end{array}$ \\
\hline 7 & $\begin{array}{c}66.01 \\
(57.89-81.67)\end{array}$ & $\begin{array}{c}83.36 \\
(78.87-114.31)\end{array}$ \\
\hline 8 & $\begin{array}{c}84.42 \\
(75.01-103.95)\end{array}$ & $\begin{array}{c}108.09 \\
(100.69-153.87)\end{array}$ \\
\hline
\end{tabular}




\section{Figure 1. Scenario and WTP questions}

We will now ask some questions regarding your household's willingness to avoid power outages. Imagine that there is a service with a backup electricity board that can be used in the case of a power outage. This electricity board would cover the households' need for electricity during the whole outage. You will only pay to the power company if an outage occurs. If you do not want to pay anything, your household will suffer from power outages. There are two types of outages, and we will ask you questions for both of these:

- Planned outage: An outage that you have been notified in advance about.

- Unplanned outage: An outage that comes as a surprise and that you have not been notified in advance about.

Imagine that an outage occurs on an evening in January and that it starts at $6 \mathrm{pm}$. For each question we ask you to answer how much your household would be willing to pay in order to avoid this outage by connection to the service. We ask you to consider your answers as carefully as possible and to remember that it is possible to answer zero kronor as well.

\section{Planned outages}

How much would your household be willing to pay in order to avoid a power outage that starts at 6 pm on an evening in January? You know in advance that the outage will occur. We ask you to answer all $\underline{4}$ questions below.

\begin{tabular}{l|l|r}
\hline & \multicolumn{1}{|c|}{ Duration of outage } & \multicolumn{2}{c}{$\begin{array}{c}\text { I'm willing to pay } \\
\text { (round off to whole numbers) }\end{array}$} \\
\hline Question 1 & 1 hour & SEK \\
\hline Question 2 & 4 hour & SEK \\
\hline Question 3 & 8 hour & SEK \\
\hline Question 4 & 24 hour & SEK \\
\hline
\end{tabular}

\section{Unplanned outages}

How much would your household be willing to pay in order to avoid a power outage that starts at 6 pm on an evening in January? You do not know in advance that the outage will occur. We ask you to answer all

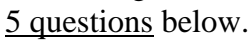

\begin{tabular}{l|l|r}
\hline \multicolumn{1}{|c|}{ Duration of outage } & $\begin{array}{c}\text { I'm willing to pay } \\
\text { (round off to whole } \\
\text { numbers) }\end{array}$ \\
\hline Question 5 & 1 hour & SEK \\
\hline Question 6 & 4 hours & SEK \\
\hline Question 7 & 8 hours & SEK \\
\hline Question 8 & 24 hours & SEK \\
\hline Question 9 & $\begin{array}{l}\text { Between 2 and 6 hours. It is equally likely that the power } \\
\text { returns after 2 hours as after 6 hours, or any time in between. }\end{array}$ & SEK \\
\hline
\end{tabular}

